\title{
Postnatal PMTCT: Women's Perception Barriers at a Johannesburg Health Centre, South Africa
}

\author{
Benon Ngyende $^{1 *}$, Blaise Bucyubaruta ${ }^{2,3}$, Charles Mugero ${ }^{4}$ \\ ${ }^{1}$ School of Public Health, Centre for Health Policy, Faculty of Health Sciences, University of the Witwatersrand, \\ Johannesburg, South Africa \\ ${ }^{2}$ Department of Homeopathy, Faculty of Health Sciences, University of Johannesburg, Johannesburg, South Africa \\ ${ }^{3}$ School of Health Systems and Public Health, Faculty of Health Sciences, University of Pretoria, Pretoria, South Africa \\ ${ }^{4}$ Communicable Diseases, National Department of Health, Pretoria, South Africa \\ Email: ^benngyende@gmail.com
}

How to cite this paper: Ngyende, B., Bucyubaruta, B. and Mugero, C. (2020) Postnatal PMTCT: Women's Perception Barriers at a Johannesburg Health Centre, South Africa. Health, 12, 1511-1525. https://doi.org/10.4236/health.2020.1211110

Received: July 3, 2020

Accepted: November 24, 2020

Published: November 27, 2020

Copyright (c) 2020 by author(s) and Scientific Research Publishing Inc. This work is licensed under the Creative Commons Attribution-NonCommercial International License (CC BY-NC 4.0). http://creativecommons.org/licenses/by-nc/4.0/ cc) (7) (8) Open Access

\begin{abstract}
Background: Maximising women's participation and ensuring optimal outcomes will require that the women's perception barriers to postnatal prevention of Mother-to-Child Transmission (PMTCT) programme of HIV be addressed. However, little is known about women's perception barriers to postnatal PMTCT programme of HIV and how these barriers affect the women's health seeking behavior and uptake. Objective: This study sought to explore the women's perception barriers to postnatal PMTCT programme at a Johannesburg Community Health Centre during April-May, 2016. Methods: A qualitative study on 30 women (aged 20 - 39 years) was conducted at a Johannesburg community health (CHC), South Africa, during May-June 2016, after obtaining their consent. The data was analysed thematically to understand women's perception barriers to postnatal PMTCT programme. Results: The study found that inadequate counselling was perceived to be the single key health service barrier to PMTCT programme. At the individual level, adherence to ART was considered the leading women's barriers to the postnatal PMTCT. Exclusive breastfeeding was, however, perceived as important women's barriers to the postnatal PMTCT. Inadequate emotional support from families and community was a noteworthy women's perception barrier to the programme. Conclusion: The study makes two recommendations: firstly, the staff, programme managers and health policy makers need to be aware of the women's perception barriers to the postnatal PMTCT programme. Secondly, the programme should be strengthened by addressing perception barriers to the programme to enhance women participation to ensure optimal outcomes for women and their infants.
\end{abstract}




\section{Keywords}

Postnatal PMTCT Barriers, Women Perception, HIV, South Africa

\section{Introduction}

Mother-to-child-transmission (MTCT) of HIV remains a major public health challenge worldwide [1]. In 2015, at least 150,000 children became newly infected with HIV mainly through MTCT of HIV globally [1]. Furthermore, at least one million women living with HIV gave birth in the 21 highest burden countries in sub-Saharan Africa and about 170,000 chidren were newly infected with HIV in 2014 [2]. The Joint United Nations on HIV/AIDS (UNAIDS) report indicated that use of antiretroviral treatment (ART) in preventing mother to child transmission (PMTCT) of HIV is effective in prevention of mother-to-child transmission of HIV [1]. Studies have demonstrated that use of antiretrovirals (ARVS) in PMTCT programmes has the potential to significantly decrease the rate of MTCT, even in the resource-limited settings [3] [4] [5]. In fact, some studies have reported a decrease of the rate of MTCT from $25 \%$ to $2 \%$ without and with single dose treatment respectively [1]. It is thus widely acknowledged that when ART/ARV drugs are correctly taken, MTCT would be significantly prevented [1] [6]. However, there are some gaps in implementing PMTCT programmes [7] [8] [9].

South Africa, a middle-income country in sub-Saharan Africa, remains an epicentre of the epidemic with the highest number of people living with HIV in the world [10]. The HIV prevalence rate among adults of reproductive age (15 - 45 years) is 18.7\% [10]. MTCT is the main cause of HIV infection in South Africa and accounts for at least one third of all deaths in children under five [11]. In order to address this challenge, South Africa has implemented the world's largest ART/PMTCT programme since 2002 [12], and by 2010, over 95\% of public health facilities offered PMTCT services countrywide [11].

Despite the increased access to PMTCT programme, recent cohort study showed that the rate of MTCT increases after birth with postnatal age in South Africa [13]. The increasing rate of MTCT of HIV during the postnatal period remains a major concern to programme managers and policy makers [14]. The causes for increasing rates of MTCT during the postnatal period remain uncertain, but studies have attributed it to significant gaps in postnatal PMTCT service delivery that undermine access and retention-in-care [7] [8] [9]. Other studies report that a number of health services, individual-level and structural barriers, including HIV testing, counselling and sub-optimal provider-client interactions hinder access to and retention of mothers and their children in postnatal PMTCT programme [15] [16] [17] [18].

\section{Theoretical Framework}

Ferguson's literature review on women's experiences in PMTCT services catego- 
rise women's experiences into three [17]:

- Health service: covering counselling, consent, confidentiality, health worker-client interactions and health facility factors.

- Individual-level: including attitudes and beliefs, financial barriers, lack of information, competing obligations, perception of need, partner/spouse influence on the family members.

- Societal-level encompassing stigma, legal as well as policy environment.

Ferguson's literature review furthermore articulates these women's experiences as barriers to attending these PMTCT services [17]. In this report, concepts in Ferguson's literature were developed into a framework for categorising women's perceptions as well as articulate them as perception barriers to the PMTCT programme.

The PMTCT programme in South Africa has the potential to virtually eliminate the rate of HIV postnatal MTCT, if access is improved as well as retention-in-care [19]. However, to improve the effectiveness of the PMTCT programme, it is critical to understand the women's perception barriers in postnatal PMTC programme in South African context. Currently, little is known about this topic. We conducted a qualitative study involving HIV positive women who were enrolled on the postnatal PMTCT programme at a Johannesburg CHC for at least 6 weeks. The objective of the study was to explore the women's perception barriers to postnatal PMTCT programme at a Johannesburg CHC during April-May, 2016.

\section{Methods}

\subsection{Study Design}

A qualitative study design was used to explore the women's perception barriers to the postnatal programme at a Johannesburg CHC, during April-May 2016. This study design was considered appropriate for soliciting in-depth responses from the participants' perspectives about a sensitive topic [20]. Furthermore, the design has considerable ability to generate answers "what" and "how" questions [20]. For this current study, 30 women attending the postnatal PMTCT programme at a Johannesburg CHC were purposively selected to participate. Purposive sampling attempts to ensure that the information rising from the participants' interviews characterise common and differing opinions of the people under study [21].

\subsection{Study Setting and Cohort}

The study was conducted at a community health centre in one of the oldest townships of the Johannesburg Metropolitan City. The CHC is located in one of the most impoverished areas of the city [22]. According to census Statistics South Africa, the township had a population of 117,074 people in 2011 [23]. The CHC Annual Report recorded that the health centre was serving many undocumented foreign nationals who lived in the area [22]. The clinic provided antenatal care (ANC), post-natal care (PNC), HIV testing, treatment and counselling 
as well as other standard primary health care services [22].

We conducted in-depth interviews between 1 April and 30 May 2016. All women who were 18 years old and above, enrolled on the postnatal PMTCT programme at the $\mathrm{CHC}$ for a period of at least 6 weeks during April-May 2016, and were willing and signed consent forms to participate in the study were included. All women who were below 18 years old or were enrolled on the postnatal PMTCT programme at the health clinic for a period less than six weeks during April-May 2016 or were not willing and did not sign consent forms to participate in the study. Thirty women who met the inclusion criteria were purposively selected and interviewed to reach data saturation. Data saturation is reached when no new information or views emerge from the participants' interviews [24]. It was also established that data saturation was reached after discussing the information from the five focus group interviews. This sample size was considered to be sufficient for this study. Bradshaw and colleagues state that most qualitative samples are small given the emphasis on intensive interaction with the participants who are expected to be rich in information, and yet the study findings are not generalisable [25]. In addition, they contend that such a small sample size is usually adequate to answer all the research questions. The data collected during the interviews was enriched and verified by means of data triangulation. Purposive sampling makes it possible that the information arising from the participants' interviews characterise common and differing opinions of the people under study [21].

\subsection{Data Collection}

A female research assistant with considerable experience in data collection was hired to collect the data. She initially approached the women enrolled on programme to request them to participate in the study. An interview guide with open-ended questions was used to conduct the interviews in the four common languages spoken in the district (Isizulu, Xhosa, Sesotho and English). The foreign nationals were Ndebele speaking; a language similar to Isizulu which is the commonest spoken language in the country. They were also able to communicate in English. Every participant was interviewed in the language in which she was most proficient and comfortable. The interview guide consisted of key questions to serve as a check list to ensure that no essential questions were omitted during the interviews [26], and to enable the interviewer to guide the interview process without leading the participant(s). Those interviews were also audio-recorded. After conducting individual in-depth interviews, focus group discussions, comprising six to eight women were conducted with the previously interviewed women at later dates to validate or enrich the collected information. The interviews and focus group discussions took between 45 minutes to an hour and were audio-recorded. The recorded information was translated and transcribed in English. Interviews and focus group discussions were conducted in a room within the clinic to maintain the necessary privacy and confidentiality. The data from the interviews were translated and transcribed verbatim into Micro- 
soft Word and transferred into MAXQDA Version 11 software. The transcripts were continuously checked to identify issues necessitating further clarification during the future interviews and focus group discussions. The verbatim transcripts were coded using deductive and inductive methods. Deductive analysis begins with a preconceived idea or framework and then uses the data to approve or dismiss the ideas while inductive method uses the data to generate ideas [27]. In this study, Ferguson's literature review of women's experiences in PMTCT services was adopted to develop a conceptual framework which guided the analysis. Deductive themes emerge from the participants' narratives following preconceived idea or a theoretical framework while inductive themes emerge from the narratives of the participants. They may be unexpected or different from literature. However, the inductive themes are useful as they represent the issues that were most important to the participants [28] [29].

Codes were developed into sub-themes and themes. This enabled the researcher to make sure that the data analysis provided rich and meaningful results that are linked to the research objectives and grounded in the experiences of the participants. The data were systematically coded until no more new themes or ideas emerged. The emerging themes were fully reviewed to reach consensus on data interpretation. These codes therefore represented a wide range of information about postnatal PMTCT women's experiences.

\section{Results}

\subsection{Demographic Characteristics of the Study Participants}

Table 1 represents the frequency distribution of the background characteristics of participants. Thirty women participated in this study. Two-thirds $(\mathrm{n}=20$; $66.7 \%$ ) of the participants were South African citizens. Almost all women ( $\mathrm{n}=$ 28 ; 93\%) were not married. Twenty out of 30 (66.7\%) women were employed.

The participants were aged between 20 and 39 years. All the participants had education levels above primary school; the minimum education level was grade nine (high school) and the highest education level was third year of university. Almost all women $(n=28 ; 93 \%)$ were tested HIV positive during their pregnancy.

\subsection{Women's Perception Barriers to Postnatal PMTCT Programme}

Table 2 represents the analysis of the women's perception barriers to postnatal PMTCT programme at three levels, namely health services, individual-level and societal-levels. It also depicts the frequency of women's perception barriers to the postnatal PMTCT programme at the CHC.

\subsection{Main Theme and Categories}

Table 3 shows the main theme and categories or sub-themes. Under the main theme of postnatal PMTCT programme women's perception barriers, three categories emerged (Table 3 ). 
Table 1. Background characteristics of the study participants $(n=30)$.

\begin{tabular}{|c|c|c|}
\hline \multicolumn{3}{|l|}{ Age group } \\
\hline $20-24$ & 4 & 13.3 \\
\hline $25-29$ & 10 & 33.3 \\
\hline $30-34$ & 12 & 40 \\
\hline $35-39$ & 4 & 13.3 \\
\hline \multicolumn{3}{|l|}{ Education status } \\
\hline Primary & 0 & 0 \\
\hline Secondary & 28 & 93 \\
\hline Tertiary & 2 & 7 \\
\hline \multicolumn{3}{|l|}{ Marital status } \\
\hline Married & 2 & 7 \\
\hline Not married & 28 & 93 \\
\hline \multicolumn{3}{|l|}{ Employment status } \\
\hline Employed & 20 & 67 \\
\hline Unemployed & 10 & 7 \\
\hline \multicolumn{3}{|l|}{ Citizenship } \\
\hline South African & 20 & 67 \\
\hline Non-South Africa & 10 & 33 \\
\hline \multicolumn{3}{|c|}{ No of postnatal PMTCT clinic visits } \\
\hline 2 & 12 & 40 \\
\hline 3 & 12 & 40 \\
\hline 4 & 4 & 13 \\
\hline 6 & 2 & 7 \\
\hline \multicolumn{3}{|l|}{ Time of HIV diagnosis } \\
\hline Voluntary & 2 & 7 \\
\hline \multirow[t]{2}{*}{ ANC (pregnancy) } & 28 & 93 \\
\hline & $\mathbf{N}=30$ & \\
\hline
\end{tabular}

PMTC, prevention of mother-to-child transmission; HIV, human immunodeficiency syndrome; ANC, antenatal clinic.

Table 2. Proportion of women who perceived the postnatal PMTCT programme barriers $(\mathrm{n}=30)$.

\begin{tabular}{lll}
\hline Health service barriers & \multicolumn{1}{c}{ Individual-level barriers } & \multicolumn{1}{c}{ Societal-level barriers } \\
\hline $\begin{array}{l}\text { Perceived inadequate } \\
\text { counselling }(\mathrm{n}=30)\end{array}$ & $\begin{array}{l}\text { Perceived challenging adherence to ART } \\
(\mathrm{n}=30)\end{array}$ & $\begin{array}{l}\text { Perceived inadequate family } \\
\text { Challenging exclusive breast Feeding }(\mathrm{n}=24)\end{array}$ \\
\hline
\end{tabular}

ART, antiretroviral therapy.

Table 3. The main theme and categories

\begin{tabular}{cl}
\hline Theme & \multicolumn{1}{c}{ Categories } \\
\hline Postnatal PMTCT & 1) Health service perception barriers \\
programme women's perception barriers & 2) Individual-level perception barriers \\
& 3) Societal-level perception barriers \\
\hline
\end{tabular}

PMTC, prevention of mother-to-child transmission. 
The first category related to women's health service perception barriers to the postnatal PMTCT programme. Second category captured the individual-level while the third category was societal-level perceptions barriers.

\subsection{Health Service Perception Barriers}

At the health service level, inadequate counseling was perceived to the only key women's barrier to postnatal PMTCT programme at the health centre. All the women felt that they received inadequate postnatal PMTCT counselling at the $\mathrm{CHC}$ and that they needed more ongoing counseling and information about infant feeding options, follow-up clinic visits and testing dates, treatment adherence and support.

“... I have not received counselling at this clinic since I delivered" (P007; 29 years old).

Furthermore, six participants said that the postnatal PMTCT staff provided them with inadequate information regarding the choice of infant feeding options. All the participants indicated that the PMTCT staff told them to choose between exclusive breastfeeding and formula feeding. However, they said that they were not provided with adequate information about the specific conditions for formula feeding. In fact, one of the participants said:

"... they [the PMTCT staff] told me, it is up to me whether I breastfeed or give him formula for six months, and then start giving him solids" (P0013; 30 years old).

Of the 28 women who responded to the question about the infant follow-up and testing dates, 8 reported that the postnatal PMTCT staff did not give them information about infant testing dates.

"They [PMTCT staff] did not tell me anything. I just thought it would make sense to test her when she turns one" (P002; 24 years old).

\subsection{Individual-Level Perception Barriers}

Adherence to ART was perceived to be the leading women's barriers PMTCT programme at the clinic at the individual-level. All the participants reported that adherence to ART was challenging, especially at the beginning of the programme.

"... At the beginning ... in the first year, it was really difficult but on the second year and following years, it becomes normal. I think now it is close to 10 years" (P0013; 30 years old).

“... At the beginning, I didn't feel okay ... I even lost weight, stressed, thinking about that thing [prophylaxis and ARVs], I ended up setting an alarm to make sure I don't forget' (P0011; 24 years old).

Exclusive breastfeeding was perceived to the second leading barrier to postnatal PMTCT programme at the clinic. The majority $(n=24)$ of the women considered exclusive breastfeeding to be difficult and emotionally challenging.

... No, that [exclusive breastfeeding] is not alright. You find that sometimes 
she (infant) cries because she's not quite full. And she just continues crying. So you just don't have a choice. She cries all the time, she just cries. You can see that she is not quite full. And there is nothing you can do because they [PMTCT staff] said she must not eat anything (P004; 33 years old).

... It is difficult to only [exclusively] breastfeed the baby for six months because sometimes he [infant] looks like he hasn't had enough but for the sake of his health it is important that you do it. I do not want to lie. I saw him crying every day, crying during the day, crying during the evening when he turned four months, I realised that it is not working. I ended up buying him purity, I gave him, and then he ate and stopped crying (P0011; 24 years old).

\subsection{Societal-Level Perception Barriers}

At the societal-level, inadequate emotional support from their partners and families was perceived to the only noteworthy women's barrier to postnatal PMTCT programme at the clinic. More than half $(n=18)$ of the women said that they got inadequate emotional support from their families and communities.

... I feel I do not receive enough support. When, for example, I ask them [spouse or family members] to give me transport [money] to bring the baby to the clinic. They tell me to walk ... They say they have no money even when they have ... (P003; 27 years old).

However, the rest $(\mathrm{n}=12)$ of the women felt that they received enough emotional support from their partners and family.

“... I can't complain. I feel they [family members] are always there for me. They really support me when $P m$ feeling down ..." (P001; 27 years old).

\section{Discussion}

This study sought to explore women's perception barriers to postnatal PMTCT programme at a Johannesburg CHC during the period April-May 2016

\subsection{Health Service Perception Barriers}

The study found that inadequate postnatal PMTCT counselling was perceived as the most prominent women's barrier at the $\mathrm{CHC}$ at the health service level. All the participants said that the counselling was mainly provided during pregnancy period when women were attending the ANC visits. The finding of this study is consistent with the results from other studies conducted in developing countries [30] [31], including South Africa [32]. For example, Anderson et al.'s findings reported existence of postnatal counselling gaps in Jamaica [31]. In Uganda, Larsson et al's study found inadequate postnatal PMTCT counseling [30]. Similarly, Chopra et al.'s study reported the poor quality of the postnatal PMTCT counselling in South Africa [32]. It is noteworthy mentioning, however, that the finding of the current study is not in agreement with the South African National and Provincial (Gauteng) PMTCT policy guidelines which promote the provision of full and adequate information during the postnatal PMTCT counseling 
period [12]. The perceived inadequate counselling can be addressed by providing ongoing comprehensive counseling throughout the postnatal period. The comprehensive counselling incorporates HIV prevention, treatment, care and support [12]. Efforts should be made to comply with the South African National PMTCT policy guidelines, which stipulate that immediate to post-delivery care and before leaving the health facility, all women must be counselled on the need for consistent maternal adherence to ART and infant prophylaxis to reduce risk of MTCT; the importance of exclusive breastfeeding for the first 6 months, the dangers of mixed breastfeeding and need for follow clinic visits [12]. In addition, if the mother or caregiver is concerned with the infant's health, including poor feeding, they should urgently present to a health centre. Attempts should be made to address any concerns and feeding before the women leave the health facility and during the scheduled follow-up clinic visits [12].

\subsection{Individual-Level Perception Barriers}

At the individual-level, adherence to ART was perceived to be the leading women's barrier to the postnatal PMTCT programme at the clinic. All women reported experiencing difficulty to adhere to taking medication as prescribed. Some women, for instance, reported that they became sickly, dizzy and stressed at the beginning of the programme. These findings are in agreement with other studies conducted in different countries [33] [34] [35] [36] including South Africa [37]. From the health policy perspective, it is noteworthy mentioning that the results of the current study highlight the importance of ART effects and their management according to the ART management guidelines [12]. The challenging adherence to ART can be addressed by implementing the four South African PMTCT policy strategies [12]:

1) Provision of quality postnatal counseling, including spending more time with the patients and explain the disease, the goals of the therapy and need for adherence, discussion of the role of viral-load and suppression, and making patients understand the possible implications of non-adherence;

2) Supporting patients with adherence tools; including encouraging patients to attend and participate in support groups, encouraging self-reporting, encouragement of treatment buddy and reinforcing maintenance of a daily dose daily;

3) Imparting knowledge to patients to ensure that the patients acquire sufficient and better understanding regarding why they should have to take ART, how it works and how it benefits them; and

4) Modifying patients' behavior; including empowering them to manage their condition themselves, ensuring that patients understand the risk of not taking their medications as prescribed, address their fears and concerns and provide ongoing encouragement and recognition for adherence.

Exclusive breastfeeding was perceived to be the second leading women's barrier to PMTCT programme at the individual-level. The majority of the women considered exclusive breastfeeding to be difficult and emotionally challenging. 
The participants reported that the challenge was due to persistent crying of the infants after exclusive breastfeeding and the mothers' perception that the breast milk as insufficient. These results are in keeping with Siziba et al.'s study which reported that the mothers perceived exclusive breastfeeding as insufficient [37]. Based on the findings of the current study, it is noteworthy mentioning that postnatal PMTCT counselling should put more emphasis on the sufficiency of exclusive breastfeeding during the first six months even though the infants may continue to cry. The mothers need to understand that whenever infants cry, it does not necessarily mean that they are hungry. The perceived difficulty and the emotional challenge of exclusive breastfeeding can be addressed by providing ongoing comprehensive postnatal counselling on infant feeding. This is consistent with a study in Dehli, India which found that infant feeding counselling was an important predictor of good infant feeding practices [38]. Efforts should be made to implement the South African PMTCT policy guidelines stipulate that immediate to post-delivery care and before leaving the health facility, all women must counselled on the importance of exclusive breastfeeding for the first six months, and the dangers of mixed breastfeeding [12]. In addition, if the mother or caregiver is concerned with the infant's health, including poor feeding, they should urgently present to a health centre [12]. These services must form part of routine for ongoing counselling and support for women seeking postnatal PMTCT services.

\subsection{Societal-Level Perception Barriers}

Inadequate emotional support was perceived to be a noteworthy women's barrier to postnatal PMTCT at societal-level. The study revealed that more than a half of the women felt that they did not receive adequate emotional support from families and community which hindered access to the postnatal PMTCT programme at the CHC. This finding is consistent with Peltzer and Shikwane's study which noted that HIV positive mothers perceived a negative emotional support from the partner and or family during postnatal [39] [40]. Gourlay and colleagues' study proposed that involving family and community members would increase support for the patience as well as PMTCT uptake [15]. This is consistent with the South African national PMTCT policy guidelines underscore the importance of male involvement in PMTCT services [12]. Thus, from health policy perspective, mothers including those who are HIV positive, should be supported by partner and family for better use and acceptance of maternal health services such as postnatal PMTCT programme [39] [40].

\subsection{Study Strengths and Limitations}

The researchers used a research assistant to help in conducting the study, translate and transcribe all the interviews. This could have introduced possible errors in the study. This source of error was minimised given that the research assistant had considerable experience in the qualitative interviewing process and had a 
debriefing with the researcher after every interview.

The study was conducted in one community health centre, rendering the study findings and conclusions not transferable, but these findings may be relevant to other PMTCT programme contexts not covered by this study.

The recall bias was considered one of possible sources of error given that some of the participants could not have been able to remember all the information regarding the postnatal PMTCT programme. However, this was minimised by probing and asking open-ended questions.

Social desirability could have been seen as a source of error because the participants tend to provide the responses that are perceived as impressive [41]. However, this source of error was minimised by the research assistant asking open-ended questions and probing.

\section{Conclusion}

Women enrolled on postnatal PMTCT programme at a Johannesburg CHC experienced difficulties in accessing PMTCT services mainly at health service and individual levels. Inadequate counselling was perceived to be only key women's barrier to PMTCT programme at the health service level; while adherence to ART and exclusive breastfeeding were perceived to be the leading women's barriers at the individual level. On the other, inadequate emotional support was perceived to be a noteworthy barrier to postnatal PMTCT at the societal-level. To improve women's participation and ensure optimal outcomes for women and their infants, programme managers, staff and policy-makers need to urgently address these perception barriers to the postnatal PMTCT programme.

\section{Recommendations}

This study explored postnatal PMTCT programme women's perception barriers at a Johannesburg CHC at three different levels. We suggested the possible solutions to address women's perception barriers to PMTCT programme at the three levels: health services, individual and societal levels

\subsection{Health Service Level}

At health service level, inadequate counselling was the only key women's perception barrier to PMTCT programme at a Johannesburg CHC. It is noteworthy commenting that significant progress has been made at the $\mathrm{CHC}$ to improve the PMTCT service delivery in the face of recognised resources constraints such as infrastructure, financing and human resource. However, efforts to improve women's knowledge and information about postnatal PMTCT services should be strengthened. Health service managers should revise the implementation of postnatal PMTCT counseling to be aligned with the existing national PMTCT guidelines. Emphasis should be put on postnatal counselling to ensure that the participants get adequate and clear information including ART and infant feeding methods. 


\subsection{Individual-Level}

At the individual level, adherence to ART and exclusive breastfeeding were the two leading women's perception barriers to postnatal PMTCT programme at a Johannesburg CHC. From a policy perspective, all women should receive comprehensive postnatal counselling on the importance of maternal adherence to ART and infant prophylaxis as well as the potential of MTCT transmission of HIV through breastfeeding. In addition, the health workers should provide women with the ongoing psycho-social support to reinforce adherence to ART and exclusive breastfeeding. Furthermore, women who experience challenges to adhere to ART or exclusive breastfeeding should be encouraged to report to the health workers urgently.

\subsection{Societal-Level}

At the societal level, inadequate emotional support from the family and community was a noteworthy women's perception barriers to PMTCT. It is hence necessary that the family and community provide support with household chores and childcare while the women are attending the PMTCT services. This can be improved by involving family and community members in PMTCT services In addition, families and communities should be sensitized to create an enabling environment for the women attending postnatal PMTCT programme.

\section{Acknowledgements}

We would like to thank the management and the City of Johannesburg District Research and Ethics Committee (DRC) for allowing us to carry out the study. We also thank the management of the Center for Health Policy (CHP); School of Public Health, University of Witwatersrand for their co-operation and mothers for accepting to take part in the study. Furthermore, we are indebted to the South African Research Chair Initiative (SAChil) and the National Research Foundation NRF for funding the study.

\section{Authors' Contribution}

B.N. made conceptual contributions, writing, data analysis, reviewed and oversaw the entire writing process.

B.B. contributed substantially to the structuring, reviewing, formatting and references of the article.

C.M. contributed to reviewing and formatting of the article.

\section{Conflicts of Interest}

The authors declare that they have no financial or personal relationship(s) that may have influenced them in the writing this article.

\section{References}

[1] Joint United Nations Programme on HIV/AIDS (2015) Progress Report on the 
Global Plan towards the Elimination of New HIV Infection among Children and Keeping Their Mothers Alive. Joint United Nations Programme on HIV/AIDS, Geneva.

https://www.unaids.org/sites/default/files/media asset/JC2385 ProgressReportGlob alPlan en 0. pdf

[2] Joint United Nations Programme on HIV/AIDS (2016) Fact Sheet: Children and HIV. Joint United Nations Programme on HIV/AIDS, Geneva. https://www.unaids.org/sites/default/files/media asset/FactSheet Children en.pdf

[3] Kanshana, S. and Simonds, R.J. (2002) National Program for Preventing Mother-Child HIV Transmission in Thailand: Successful Implementation and Lessons Learned. AIDS, 16, 953-959. https://doi.org/10.1097/00002030-200205030-00001

[4] Dao, H., Mofenson, L.M., Ekpini, R., Gilks, C.F., Barnhart, M., Bolu, O., et al. (2007) International Recommendations on Antiretroviral Drugs for Treatment of HIV-Infected Women and Prevention of Mother-to-Child HIV Transmission in Resource-Limited Settings: 2006 Update. American Journal of Obstetrics and Gynecology, 197, S42-S55. https://doi.org/10.1016/j.ajog.2007.03.001

[5] Thistle, P., Bolotin, S., Lam, E., Schwarz, D., Pilon, R., Ndawana, B., et al. (2011) Highly Active Anti-Retroviral Therapy in the Prevention of Mother-to-Child Transmission of HIV in Rural Zimbabwe during the Socio-Economic Crisis. Medicine, Conflict, and Survival, 27, 165-176. https://doi.org/10.1080/13623699.2011.631752

[6] World Health Organization (2015) Guideline on When to Start Antiretroviral Therapy and on Pre-Exposure Prophylaxis for HIV. World Health Organization, Geneva. https://www.who.int/hiv/pub/guidelines/earlyrelease-arv/en/

[7] Chi, B.H., Bolton-Moore, C. and Holmes, C.B. (2013) Prevention of Mother-to-Child HIV Transmission within the Continuum of Maternal, Newborn, and Child Health Services. Current Opinion in HIV and AIDS, 8, 498-503. https://doi.org/10.1097/COH.0b013e3283637f7a

[8] Barker, P.M. and Mate, K. (2012) Eliminating Mother-to-Child HIV Transmission will Require Major Improvements in Maternal and Child Health Services. Health Affairs, 31, 1489-1497. https://doi.org/10.1377/hlthaff.2012.0267

[9] Wettstein, C., Mugglin, C., Egger, M., Blaser, N., Vizcaya, L.S., Estill, J., et al. (2012) Missed Opportunities to Prevent Mother-to-Child-Transmission: Systematic Review and Meta-Analysis. AIDS, 26, 2361-2373. https://doi.org/10.1097/QAD.0b013e328359ab0c

[10] Statistics South Africa (2016) Mid-Year Estimates 2016. Statistics South Africa, Pretoria. http://www.statssa.gov.za/?p=8176

[11] Shisana, O., Rehle, T., Simbayi, L.C., Zuma, K., Jooste, S., Zungu, N., et al. (2014) South African National HIV Prevalence, Incidence and Behaviour Survey, 2012. HSRC Press, Cape Town.

[12] National Department of Health, South Africa (2014) National Consolidated Guidelines for the Prevention of Mother-to-Child Transmission of HIV (PMTCT) and the Management of HIV in Children, Adolescents and Adults. http://www.kznhealth.gov.za/family/HIV-Guidelines-Jan2015.pdf

[13] Goga, A., Jackson, D., Lombard, C., Ramokolo, V., Ngandu, N., Sherman, G., et al. (2016) Highest Risk of Mother to Child Transmission of HIV or Death in the First 6 Months Postpartum: Results from 18 Month Follow-Up of an HIV-Exposed National Cohort, South Africa. Journal of the International AIDS Society, 19, 27-28.

[14] Nhemachena, D. (2014) The Rate of Postnatal MTCT of HIV Is a Great Concern to 
Programme Managers and Policy Makers within Johanneburg Health District.

[15] Gourlay, A., Birdthistle, I., Mburu, G., Iorpenda, K. and Wringe, A. (2013) Barriers and Facilitating Factors to the Uptake of Antiretroviral Drugs for Prevention of Mother-to-Child Transmission of HIV in Sub-Saharan Africa: A Systematic Review. Journal of the International AIDS Society, 16, 18588. https://doi.org/10.7448/IAS.16.1.18588

[16] Stringer, E.M., Ekouevi, D.K., Coetzee, D., Tih, P.M., Creek, T.L., Stinson, K., et al. (2010) Coverage of Nevirapine-Based Services to Prevent Mother-to-Child HIV Transmission in 4 African Countries. JAMA, 304, 293-302. https://doi.org/10.1001/jama.2010.990

[17] Ferguson, L. and World Health Organization (2013) Women's Experiences in Services for Preventing the Mother-to-Child Transmission of HIV: A Literature Review. World Health Organization, Genva.

[18] De Lemos, L.M., Lippi, J., Rutherford, G.W., Duarte, G.S., Martins, N.G., Santos, V.S., et al. (2013) Maternal Risk Factors for HIV Infection in Infants in Northeastern Brazil. International Journal of Infectious Diseases, 17, e913-e918. https://doi.org/10.1016/j.ijid.2013.04.015

[19] De Cock, K.M., Fowler, M.G., Mercier, E., de Vincenzi, I., Saba, J., Hoff, E., et al. (2000) Prevention of Mother-to-Child HIV Transmission in Resource-Poor Countries: Translating Research into Policy and Practice. JAMA, 283, 1175-1182. https://doi.org/10.1001/jama.283.9.1175

[20] Thornhill, A., Saunders, M. and Lewis, P. (2009) Research Methods for Business Students. Prentice Hall, London.

[21] Joubert, G., Ehrlich, R., Katzenellenbogen, J. and Karim, S.A. (2007) Epidemiology: A Research Manual for South Africa. Oxford University Press, Southern Africa.

[22] Alexandra Health Community Health Centre and University Clinic Annual Report 2012.

[23] Statistics South Africa (2011) Census 2012. https://www.statssa.gov.za/publications/P03014/P030142011.pdf

[24] Coyne, I. (1997) Samplying a Qualitative Research. Purposiveful and Theoetical Sampling, Merging or Clear Boundaries. Journal of Advanced Nursing, 26, 623-630. https://doi.org/10.1046/j.1365-2648.1997.t01-25-00999.x

[25] Bradshaw, C., Atkinson, S. and Doody, O. (2017) Employing a Qualilitative Descriptive Approach in Health Care Research. Global Qualititaivr Nursing Research, 4, 1-8. https://doi.org/10.1177/23333393617742282

[26] De Vos, A.S., Delport, C., Fouché, C.B. and Strydom, H. (2011) Research at Grass roots: A Primer for the Social Science and Human Professions. Van Schaik Publishers, Hatfield.

[27] Holloway, I. (1997) Basic Concepts for Qualitative Research. Wiley-Blackwell, Hoboken.

[28] Hennink, M., Hutter, I. and Bailey, A. (2020) Qualitative Research Methods. SAGE Publications Limited, Thousand Oaks.

[29] Starks, H. and Trinidad, S.B. (2007) Choose Your Method: A Comparison of Phenomenology, Discourse Analysis, and Grounded Theory. Qualitative Health Research, 17, 1372-1380. https://doi.org/10.1177/1049732307307031

[30] Anderson, G., Caswell, G., Edwards, O., Hsieh, A., Hull, B., Mallouris, C., et al. (2012) Community Voices: Barriers and Opportunities for Programmes to Successfully Prevent Vertical Transmission of HIV Identified through Consultations among People 
Living with HIV. Journal of the International AIDS Society, 15, 17991. https://doi.org/10.7448/IAS.15.4.17991

[31] Larsson, E.C., Thorson, A., Pariyo, G., Conrad, P., Arinaitwe, M., Kemigisa, M., et al. (2012) Opt-Out HIV Testing during Antenatal Care: Experiences of Pregnant Women in Rural Uganda. Health Policy and Planning, 27, 69-75. https://doi.org/10.1093/heapol/czr009

[32] Chopra, M., Doherty, T., Jackson, D. and Ashworth, A. (2005) Preventing HIV Transmission to Children: Quality of Counselling of Mothers in South Africa. Acta Paediatrica, 94, 357-363. https://doi.org/10.1111/j.1651-2227.2005.tb03080.x

[33] Painter, T.M., Diaby, K.L., Matia, D.M., Lin, L.S., Sibailly, T.S., Kouassi, M.K., et al. (2004) Women's Reasons for Not Participating in Follow up Visits before Starting Short Course Antiretroviral Prophylaxis for Prevention of Mother to Child Transmission of HIV: Qualitative Interview Study. BMJ, 329, 543.

https://doi.org/10.1136/bmj.329.7465.543

[34] Mrisho, M., Obrist, B., Schellenberg, J.A., Haws, R.A., Mushi, A.K., Mshinda, H., et al. (2009) The Use of Antenatal and Postnatal Care: Perspectives and Experiences of Women and Health Care Providers in Rural Southern Tanzania. BMC Pregnancy and Childbirth, 9, Article No. 10. https://doi.org/10.1186/1471-2393-9-10

[35] Ngarina, M., Popenoe, R., Kilewo, C., Biberfeld, G. and Ekstrom, A.M. (2013) Reasons for Poor Adherence to Antiretroviral Therapy Postnatally in HIV-1 Infected Women Treated for Their Own Health: Experiences from the Mitra Plus Study in Tanzania. BMC Public Health, 13, Article No. 450. https://doi.org/10.1186/1471-2458-13-450

[36] Hodgson, I., Plummer, M.L., Konopka, S.N., Colvin, C.J., Jonas, E., Albertini, J., et al. (2014) A Systematic Review of Individual and Contextual Factors Affecting ART Initiation, Adherence, and Retention for HIV-Infected Pregnant and Postpartum Women. PLoS ONE, 9, e111421. https://doi.org/10.1371/journal.pone.0111421

[37] Siziba, L., Jerling, J., Hanekom, S. and Wentzel-Viljoen, E. (2015) Low Rates of Exclusive Breastfeeding Are Still Evident in Four South African Provinces. South African Journal of Clinical Nutrition, 28, 170-179. https://doi.org/10.1080/16070658.2015.11734557

[38] Kumar, A., Singh, B., Yadlapallis, S. and Kusuma, Y.S. (2015) Counselling Services in PMTCT in Dehli, India: An Assessment through a Modified Version of UNICEF-PPTCT Toll. Journal of Epidemiology and Global Health, 5, 3-13.

https://doi.org/10.1016/j.jegh.2014.12.001

[39] Peltzer, K., Mosala, T., Shisana, O., Nqueko, A. and Mngqundaniso, N. (2007) Barriers to Prevention of HIV Transmission from Mother to Child (PMTCT) in a Resource Poor Setting in the Eastern Cape, South Africa. African Journal of Reproductive Health, 11, 57-66. https://doi.org/10.2307/30032488

[40] Bucyibaruta, B.J., Eyles, J., Harris, B., Kabera, G., Oboirien, K. and Ngyende, B. (2018) Patients' Perspectives of Acceptability of ART, TB and Maternal Health Services in a Subdistrict of Johannesburg, South Africa. BMC Health Services Research, 18, Article No. 839. https://doi.org/10.1186/s12913-018-3625-5

[41] Fisher, R.J. (1993) Social Desirability Bias and the Validity of Indirect Questioning. Journal of Consumer Research, 20, 303-315. https://doi.org/10.1086/209351 